\title{
EduSearch - Um sistema de informação para pesquisa de artigos científicos da área da educação
}

\author{
Gabriel Menezes da Silva ${ }^{1}$, Efraim Santana Leite Filho ${ }^{1}$, Adriano Silva Lima ${ }^{1}$ \\ ${ }^{1}$ Universidade Tiradentes (UNIT) - Aracaju, SE - Brasil \\ gabriel.menezes96@souunit.com.br, efraimleitedgmail.com, \\ adrianosl@gmail.com
}

\begin{abstract}
EduSearch allows users to search and view the scientific articles of journals classified in the Qualis Education of the 2013-2016 quadrennium, also displaying their international classification indexes and their strata.

Resumo $O$ EduSearch permite que os usuários pesquisem e visualizem os artigos científicos dos periódicos que estejam classificados no Qualis Educação do quadriênio 2013-2016, exibindo também seus índices de classificação internacionais e seus estratos.
\end{abstract}

\section{Introdução}

No mercado já existem aplicativos como Researcher e ACS Mobile, em que é possível pesquisar e visualizar artigos científicos internacionais, mas, aplicativos onde o âmbito são produções nacionais avaliadas pela Qualis Periódicos são escassos. Diante desse contexto, surgiu o EduSearch, aplicativo para dispositivos móveis com os sistemas operacionais Android e iOS, que tem o objetivo de permitir a pesquisa e visualização dos artigos de periódicos científicos da Qualis Periódicos da Educação do quadriênio (2013-2016). Fornecendo também como funcionalidade a visualização das classificações dos impactos internacionais dessas produções que são atribuídas pelos diversos e principais índices bibliométricos internacionais (Eigenfactor, H-Index, JIF, entre outros) [COLEPICOLO 2015].

\section{Descrição do aplicativo e Contribuição Tecnológica}


O aplicativo possui três telas: Uma onde é possível pesquisar os periódicos científicos e visualizar os artigos contidos neles; Outra onde é possível pesquisar pelos periódicos e visualizar os valores dos seus índices bibliométricos e do seu estrato da Qualis(Eigenfactor, HIndex, JIF, entre outros); E outra tela que possui algumas informações sobre a produção do aplicativo. As maiores contribuições tecnológicas feitas pelo EduSearch que podem ser apontadas consistem na facilidade do seu uso e na sua contribuição para o âmbito acadêmico nacional.

\section{Conclusões e Trabalhos Futuros}

Com o EduSearch a vida de um pesquisador brasileiro será facilitada, pois, na palma de sua mão está o meio pelo qual ele pode visualizar diversos artigos nacionais da área da educação e também é o meio pelo qual ele irá realizar a escolha do próximo periódico para publicar o seu artigo científico. Os trabalhos futuros em relação ao EduSearch são os seguintes: A constante atualização e renovação dos dados existentes, adicionamento de artigos de diversas áreas de conhecimento da Qualis Periódicos na base de dados consumida e também no lançamento de um site com o mesmo propósito do aplicativo em questão.

\section{Referências}

COLEPICOLO, Eliane. Information reliability for academic research: review and recommendations. 2015. Disponível em: https://www.emeraldinsight.com/doi/abs/10.1108/NLW-05-2015-0040. Acesso em: 10 mar. 2019. 